\title{
Experimental drop test investigation into wetdeck slamming loads on a generic catamaran hullform
}

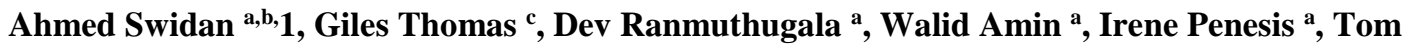 \\ Allen d, Mark Battley d \\ ${ }^{a}$ Australian Maritime College, University of Tasmania, TAS 7248, Australia \\ ${ }^{b}$ Arab Academy for Science, Technology and Maritime Transport, Alexandria 1029, Egypt \\ ${ }^{c}$ University College London, London WC1E 7JE, UK \\ ${ }^{d}$ Centre for Advanced Composite Materials, University of Auckland, Auckland 1023, New Zealand
}

\begin{abstract}
A series of drop-test experiments was performed to investigate the hydrodynamic loads experienced by a generic wave-piercer catamaran hullform during water impacts. The experiments, which focus on the characterisation of the unsteady slam loads on an arched wetdeck, were conducted using a Servo-hydraulic Slam Testing System (SSTS) that allows the model to enter the water at a range of constant speeds up to $10 \mathrm{~m} / \mathrm{s}$. The systematic and random uncertainties associated with the drop test results are quantified in detail. The relationships between water-entry velocity and both slam force and pressure distributions are presented and discussed with a strong relationship between the slam force peak magnitudes and impact velocity being observed. In addition the three dimensionality of the water flow in these slam impact events is characterised.
\end{abstract}

Keywords: Catamaran; Slamming forces; Pressure distribution; Water impact

\section{Introduction}

Over the past two decades there has been increased military and commercial interest in lightweight high-speed catamarans, with the aspiration to increase their operational speed and extend their service areas to open oceans. Structural optimisation is a key factor in achieving this, so that deadweight-to-lightship ratios can be maximised whilst ensuring resilience to wave-induced loadings. This relies on the accurate knowledge of

1 Corresponding author.

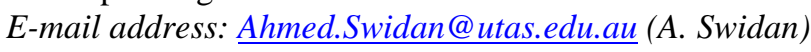


the wave loads, which for a high-speed catamaran are generally dominated by wetdeck slamming. A catamaran experiences a wetdeck slam when the wetdeck, the exposed deck area between the two demihulls, impacts with the water surface when experiencing high relative vertical motions.

To avoid the prospect of structural damage occurring, which is a possibility even when these vessels are designed to classification society rules, as stated by Yamamoto et al. (1985), Rothe et al. (2001) and Thomas et al. (2002), it is necessary to accurately predict the wetdeck slam loading. This can be accomplished through full-scale trials, model experiments and/or numerical techniques.

Full-scale measurements can provide valuable data on the loads experienced by vessels in realistic sea conditions and allow the characterisation of the parameters that influence slam severity, as performed by Jacobi et al. (2014). However due to a range of factors such as their expense, an inability to control the test environment and the difficulty of isolating the actual slam loads from complex strain gauge records, it is generally the least common method used for estimating wave slam loads.

There are two model-scale experimental techniques which are generally used to ascertain impact loads: seakeeping tests using a hydroelastic model where the wetdeck may be isolated to measure the slamming force, as presented by Lavroff et al. (2011) and French et al. (2015) and free-fall drop tests where a quasi-two-dimensional (2-d) catamaran section is dropped into a body of water, as studied by Davis and Whelan (2007). Depending on the complexity of the test system, free-fall drop tests can be relatively simple to implement and is generally considered to be a realistic approach to characterise local slamming loads. Though there are two major weaknesses of this methodology: only a two-dimensional (2-d) catamaran section is used for the tests, 
therefore three-dimensional (3-d) effects are neglected, and the vertical velocity of the test section is not controlled during the impact, so the impact velocity profile may not be relevant to that experienced by vessels in real slamming conditions.

Early examples of model drop tests are found in Chuang (1966) and Ochi and Motter (1971) to predict design pressures of flat-bottomed models and mono-hull vessels respectively. Several references to extensive 2-d and 3-d model drop test experiments can be found in the literature presented by Djatmiko (1992), Engle and Lewis (2003), Tveitnes et al. (2008), Kapsenberg (2011), Panciroli et al. (2012), Panciroli et al. (2013), Panciroli (2013), Panciroli et al. (2015), Jalalisendi et al. (2015a) and Jalalisendi et al. (2015b). However there is very limited data for multi-hull vessels. An exception is the study conducted by Whelan (2004), where a series of 2-d free-falling drop tests was conducted to evaluate the behaviour of seven catamaran model hull forms during the water-impact phase. The limitations of assuming that the wetdeck slam event is a 2-d phenomenon were highlighted by the results of a computational study conducted by Davis and Whelan (2007) when the impact loading magnitude of the 2-d simulations was found to be significantly larger than those when the three dimensionality of the section was included.

Computational Fluid Dynamics (CFD) methods have been shown to be an accurate technique for predicting the magnitude of 2-d impact events. For example Swidan et al. (2014) successfully validated the use of CFD against the two-dimensional experimental results of Whelan (2004) and Lewis et al. (2010). However to date no three dimensional water impact tests of catamaran hull forms have been conducted and as such it has not been possible to validate 3-d CFD predictions for these hull forms. 
This work was therefore motivated by the lack of non-proprietary data suitable for benchmarking catamaran vessels impacting water in 3-d flow regimes. The controlledvelocity water impact experiments reported here therefore focus on the characterisation of local slamming loads for a generic hull form of a wave-piercer catamaran during water entry. Direct measurements of hydrodynamic forces and pressure distributions are provided on an arched semi-closed wetdeck impacting water for a range of speeds and the three dimensionality of the water flow during the impact events is characterised.

\section{Model and Experimental setup}

\subsection{The test system}

The water impact experiments were conducted using the Servo-hydraulic Slam Testing System (SSTS). This system was originally developed at Callaghan Innovation, Auckland, New Zealand, and is now located at the Centre of Advanced Composite Materials, University of Auckland. This controlled-speed water impact facility consists of a circular polyethylene water tank measuring $3.5 \mathrm{~m}$ in diameter and $2.5 \mathrm{~m}$ in height. It has a servo-hydraulic system with a ram actuator supplied by pressure from two precharged accumulators. The velocity of the ram is controlled by a computer feed-back system and servo-valve, enabling constant or variable-velocity impacts to be achieved up to velocities of $10 \mathrm{~m} / \mathrm{s}$. Attached to the end of the ram is a test fixture, which slides vertically on linear bearings. The motions of the fixture are therefore restricted in all degrees of freedom except for vertical motion. More details of the SSTS can be found in Battley and Allen (2012) and Stenius et al. (2013).

Fig. 1 illustrates the main components of the SSTS. The tank was filled to a depth of $1.15 \mathrm{~m}$ with fresh water at a temperature of approximately $11^{\circ} \mathrm{C}$. The water depth was 
considered sufficient as it was comparable with water depths used in previous constant velocity drop-test experiments of similar or larger test specimens, such as those recently presented by Alaoui et al. (2015) and Tveitnes et al. (2008).

A sight window measuring $0.1 \mathrm{~m}$ width $\times 0.4 \mathrm{~m}$ height was cut into the side of the tank covered by $3 \mathrm{~mm}$ clear perspex in order to allow the high-speed camera's lens to face the model.

Although the test fixture can be used to set up different angles of trim for the model, from $0^{\circ}$ up to $40^{\circ}$ in $10^{\circ}$ increments, based on results from previous full-scale trials and seakeeping tests for this particular type of vessel (for example those conducted by Jacobi et al. (2012) which showed slamming occurring at small pitch angles, all tests were conducted at zero trim angle.

Fig. 1:

\subsection{The test model}

A generic wave-piercer catamaran model was constructed at the Australian Maritime College (AMC), with the lines plan as shown in Fig. 2. The hull form is for a wavepiercer catamaran with a centrebow similar in style to those designed by Revolution Design Pty Ltd and manufactured by Incat Tasmania. The body lines of the generic wave-piercer catamaran hull form are presented (on the right hand side) with a $25 \mathrm{~mm}$ longitudinal spacing. On the left hand side of this diagram the transverse sections on which the pressure transducers were mounted are presented. This is to clarify the geometrical variations in the sections where the transducers were located.

Fig. 2: 
The test model has a length $(L)$ of $500 \mathrm{~mm}$, beam $(B)$ of $638 \mathrm{~mm}$, height $(H)$ of 327.6 $\mathrm{mm}$ and total mass of $14.8 \mathrm{~kg}$. It was sized to ensure that there would be a gap between the model and the tank wall of double the model's overall beam. This was to minimise boundary condition effects and the possibility of wave reflections.

A three-dimensional Computer Numerically Controlled (CNC) router was used to cut the model out of 15 layers of glass reinforced plastic giving a total shell thickness of 10 mm with minimal surface roughness. This construction technique ensured high accuracy in positioning the pressure transducer locations $( \pm 0.1 \mathrm{~mm})$. In addition the model was internally stiffened by a grid of $12 \mathrm{~mm}$ thick plywood in both the longitudinal and transverse directions with a maximum spacing of 150 x $100 \mathrm{~mm}$ (see Fig. 3). All internal spaces were then filled with closed-cell expanding foam to avoid water ingress during the tests.

A limited space around the pressure transducers was partially sealed using plastic sheeting and silicon to enable access to the transducers during the tests, if required. The model was installed on the centreline of the moving test fixture, as shown in Fig. 4.

Fig. 3:

Fig. 4:

\subsection{Instrumentation}

In order to characterise the response during impact the key parameters measured in the tests were vertical force and pressure. A summary of the instruments and signal conditioning hardware is given in Table 1.

Table 1: 
The total slamming loads acting on the model in the vertical direction were acquired directly by means of three full bridge load cells installed between the model and its stiffened support in the rig, as shown in Figs. 3 and 4. Three load cells were considered to be the minimum number sufficient to avoid moments during the impact phase based on recent drop-test experiments, such as those of Huera-Huarte et al. (2011). All the total impact force measurements presented in this paper are the sum of the three load cell outputs.

To measure the impact pressure on the model five Piezotronics transducers were mounted at selected positions equally distributed by $38.7 \mathrm{~mm}$ in the $\mathrm{y}$ direction along the highest points on the wetdeck arch at each transverse section, as shown in Fig. 2. This figure also illustrates that the wetdeck arch surfaces in the vicinity of the fittings were designed to be flat to ensure the pressure transducer fittings were flush with the hull. Non-flush pressure sensors can cause separation in the flow, and hence affect the accuracy of measured pressures, see Pistani and Thiagarajan (2012) and Van Nuffel et al. (2013). The exact locations of the pressure transducers are given in Table 2, in relation to a fixed coordinate system as presented in Fig. 2 with the origin on the baseline at the bow of the starboard demihull.

Table 2:

A high-speed camera (Photron Fastcam SA5 model) with a maximum frame rate of $7500 \mathrm{fps}$ and a 1 megapixel resolution was utilised to film the impact events at $3000 \mathrm{fps}$ to preserve high resolution. This footage provided the opportunity to obtain an improved understanding of the flow behaviour beneath the arched wetdeck during the model water-entry. 
The time history of the moving model's position was measured using the servohydraulic system's linear displacement transducer. The velocity time history was obtained by differentiating the corresponding position to the corresponding time history.

The signals from all the instruments were acquired using a modular National InstrumentsTM compact data acquisition system (cDAQ 9178) with National Instruments LabVIEW software used to record the signals. Data recording was triggered once the model had travelled $50 \mathrm{~mm}$ from the start of each test. A sampling rate of 51.2 $\mathrm{kHz}$ was used; this is more than 2.5 times the sample rate used by Graczyk and Moan (2008) to reflect the real time histories of sloshing impacts, as too the minimum recommended sample rate by the Det Norske Veritas DNV (2010) is $20 \mathrm{kHz}$ to provide sufficient density of data points, especially for the pressure peaks . The measured data was automatically converted into its corresponding unit of measured data using the calibration factors that were input into the DAQ software prior to the tests.

\subsection{Test conditions}

The water impact experiments were conducted at a range of controlled water-impact velocities, with the speeds primarily being selected based on full scale impact values. A recent analysis of full-scale trials conducted by Jacobi et al. (2012) found that relative vertical velocities of up to $13 \mathrm{~m} / \mathrm{s}$ can occur. Consideration was also given to ensure that the ratio of measured loads to the maximum allowable load of the load cells ( 5 tonne) was sufficient to provide a good signal to noise ratio. Additionally the test system needed to operate in a range that would minimise any velocity variations during the water-entry process, based on a study conducted by Battley and Allen (2012).

Table 3: 
The selected range of target velocities is given in Table 3. Also provided in this table are the corresponding average velocities that were achieved during the impacts and the corresponding standard deviation $\left(v_{s t d}\right)$ of repeated tests.

The SSTS was programmed to achieve the target velocity at a point at least $100 \mathrm{~mm}$ above the free surface. The driving ram continued to maintain a constant speed for at least $250 \mathrm{~mm}$ after the demihull keels touched the water, to ensure that the wetdeck was completely submerged. The maximum allowable distance to ensure the rig was stationary after a water impacts was $810 \mathrm{~mm}$ from the datum, i.e. more than $600 \mathrm{~mm}$ from tank bottom.

After each drop test the rig was returned back to its starting point by means of the hydraulic system. A time of at least 15 minutes was allowed between drop tests to ensure that the water free-surface was calm.

\section{Uncertainty analysis}

\subsection{Random Uncertainties}

To confirm that the random uncertainty was within acceptable tolerances each condition was repeated for a minimum of three tests; this also provided confidence in the instrumentation and the recording DAQ system. The measured data from three water impact tests, for a target velocity of $4.5 \mathrm{~m} / \mathrm{s}$, are presented in Fig. 6 .

Dismantling the model from the rig, then reinstalling it and repeating the tests confirmed the repeatability of the complete system set up. This was carried out at the target velocity of $4 \mathrm{~m} / \mathrm{s}$, as presented in Figs. 8-10. The zero time and zero immersion 
refer to the instant at which demihull keels touch water, while the transducer positions used are illustrated in Fig. 5.

Fig. 5:

Fig. 6(a) shows excellent repeatability for the immersion data. In addition the velocity profile, illustrated in Fig. 6(b) (derivative of immersion), shows minimal variation between the three tests. The velocity magnitude drops by $6.5 \%$ for Test No.1 and $10 \%$ for Test No.2, in relation to the target velocity, during the impact phase. There is a direct correlation between the reduction in velocity and the development of the hydrodynamic loads between 28 and $45 \mathrm{~ms}$, which is attributed to some lag in the response of the servo-hydraulic system. The pressure peak at the transducer P1 is illustrated in Fig. 6(c), and was found to be uncertain by a maximum of $\pm 5 \%$, which is half the difference between the maximum and minimum values of pressure peaks (from repeated tests) divided by the mean value of pressure peaks. Fig. 6(d) illustrates excellent repeatability in the magnitude of the total impact force peak with uncertainty of approximately $2 \%$.

Not all of the uncertainty in force and pressure traces should be attributed to the instantaneous velocity; the velocity time series before impact can also influence jet formation and hence the amount of aerated water beneath the arched wetdeck during the impact phase.

Fig. 6:

Figs. $7-8$ show that a change of $0.35 \%$ in impact velocity can affect the peak force magnitude by up to $3 \%$. The subplot in Fig. 7 points to the immersion of the model 
during the impact phase and shows good repeatability between tests. Fig. 9 illustrates excellent repeatability between measured peak pressures with uncertainty between the magnitude of peaks of $1.5 \%$. Although there is slight temporal deviation between both pressures, the results correlate well with the velocity profiles.

Fig. 7:

Fig. 8:

Fig. 9:

Figs. 7-9 confirm that the slam loads are strongly dependent on velocity profile. Thus it is more appropriate to compare the data with respect to instantaneous velocities rather than the target velocity, which can vary slightly due to the hydraulic system response and/or any change in the point where the ram starts to accelerate.

After each test some water droplets remained on the surface of the model. The effect of these droplets was determined to be negligible with no discernible difference in the results being apparent if the model was dried or not before a test. This was probably due to the two water-jets, from the entry of the demihulls and the centrebow, mixing at the top of the archway, as shown in Fig. 10, so that the wet deck is already wet when a slam event commences.

Fig. 10:

\subsection{Systematic uncertainties}

The systematic uncertainties were estimated for all of the instrumentation, based on technical data provided by the manufacturers, and this is summarised in Table 4. As 
stated in Section 2.4, the model was installed using a stiffened support in the rig through load cells to directly measure the vertical impact loads. This rigid support in the rig is inclined by less than $1^{\circ}$ and hence considered horizontal.

Table 4:

\subsection{Velocity variations}

One of the principal factors affecting slamming loads is the impact velocity. Hence relating loads to the target velocity can be considered to be inaccurate when the measured velocity deviates from the target velocity. Fig. 11 illustrates the maximum error bounds (Equation 1) in the measured velocity corresponding to the target velocity within the selected range of velocities, i.e. from $2.5 \mathrm{~m} / \mathrm{s}$ up to $5 \mathrm{~m} / \mathrm{s}$ in $0.5 \mathrm{~m} / \mathrm{s}$ increments.

$$
\text { Error bound }=\frac{2\left(v_{\text {target }}-v_{\text {impact }}\right)}{\left(v_{\text {target }}+v_{\text {impact }}\right)} \times 100 \%
$$

Fig. 11:

Fig. 11 shows that the uncertainty range can depend to some extent on the target velocity, i.e. around $4 \%$ reduction in target velocity at $2.5 \mathrm{~m} / \mathrm{s}$, while the impact velocity decreased by approximately $11 \%$ for a target velocity of $5 \mathrm{~m} / \mathrm{s}$. This is likely due to the direct correlation between the water entry velocity and the corresponding slam load, as will be discussed in Section 4. This variation was considered acceptable when compared with other facilities such as that used by Tveitnes et al. (2008) where the velocity varied by $\pm 11 \%$ for a $5^{\circ}$ wedge section during the impact phase at lower velocities than those

used in the present work. To account for this slight change in velocity profiles all 
presented data in Section 4 corresponds to the instantaneous impact velocity rather than the target velocity.

\subsection{Filtering}

No filtering was applied to the pressure measurements during post processing to avoid the possibility of curtailing any peaks. The noise levels were seen to be negligible compared with the signal magnitude. The high sampling rate resulted in some noise in the impact load signals, therefore a low-pass Butterworth filter was applied with a cutoff frequency of $500 \mathrm{~Hz}$ (see Fig. 14) to all load signals during post processing. The results of this filtering on the loads can be seen in Fig. 12.

Fig. 12:

The filter was conducted using Matlab function named 'filtfilt' which is zero phase digital filtering, that preserves signal time-history in line with the original signal by processing current point in relation to both forward and reverse points in the frequency domain, further information can be found in Mitra and Kuo (2006).

\section{Results and discussion}

\subsection{Time History Results}

The results from three model water-impact tests at target velocities of $4,4.5$ and 5 $\mathrm{m} / \mathrm{s}$ are presented in this section. Figs. 13-15 include (a) immersion, (b) velocity, (c) vertical slam force and (d) pressure traces. The data presented starts at time instant to $=$ $0 \mathrm{~ms}$, which is the instant when the demihull keels touch the free surface. In these figures: subplots (a) illustrates the measured immersion time history, where the submergence of the model $Z_{o}=0 \mathrm{~m}$ is concurrent with $t_{o}$; the calculated velocity time 
histories are presented in subplots (b); subplots (c) illustrate the three load cell outputs and their summation of the total vertical slam force acting on the entire model; subplots (d) represent the pressure traces at five selected points along the arched wetdeck corresponding to the pressure transducer location areas shown in Figs 2, 3 and 5.

The results for an impact with a target velocity of $4 \mathrm{~m} / \mathrm{s}$ are now discussed in detail. The time history of the vertical immersion shows a linear water-entry process, as presented in Fig. 15(a). In Fig. 15(b) the velocity shows small variations of approximately $6 \%$ around a mean value of $3.85 \mathrm{~m} / \mathrm{s}$. The most significant reduction in relative velocity corresponds to the time when the slam force is at a maximum at approximately $\mathrm{t}=41 \mathrm{~ms}$.

Fig. 13:

Fig. 14:

Looking in detail at the total slam force results (Fig. 15(c)), the vertical force exhibits a series of peaks at 7, 19.5 and $41 \mathrm{~ms}$, which correspond to different incidents in the overall slam event. These incidents are shown in the high-speed photographs presented in Fig. 16. The initial small peak in the slam force at $7 \mathrm{~ms}$ corresponds to an immersion of $26 \mathrm{~mm}$, when the broad section of the demihull keels start to displace water. At 19.5 ms the centrebow keel hits the free-surface, followed by an increase in slam force until it reaches the slam force peak at $41 \mathrm{~ms}$, corresponding to $159 \mathrm{~mm}$ of immersion when the archway is filled with water and this followed by a rapid reduction in force, as presented in Fig. 15(c). 
In Figure 15(c) the individual signals from each of the three load cells are presented. The outputs of load cells LC1 and LC2, which are aligned transversely at the aft end of the model show good agreement with respect to rise time to peak load as well as the peak magnitude, indicating that the model enters the water symmetrically.

Fig. 15:

Fig. 16:

The resultant total force occurs mostly in the aft portion of the centrebow since the measured loads from the aft load cells have approximately double the magnitude of LC3 which is located close to the centre of the model.

The total vertical force indicates that the severity of the slam starts to increase rapidly at $33.8 \mathrm{~ms}$, which relates to an immersion of $130 \mathrm{~mm}$. This observation is important since it shows that for wetdeck slamming to occur, the archway does not need to be immersed to a level equivalent to the original free-surface. Instead the archway is filled before this amount of immersion occurs due to ingress of water displaced by the immersing demihulls (as shown in Fig. 16 at a time of $19.5 \mathrm{~ms}$ ) and the centrebow.

This effect was previously proposed following model experiments of a wave-piercer catamaran in irregular waves by Thomas et al. (2011). However, with no high-speed camera it was not possible to verify this phenomenon at that time. In these experiments it was confirmed through high-speed camera images, for example those taken at frames of $19.5 \mathrm{~ms}$ and $32.8 \mathrm{~ms}$, as presented in Fig. 16. The images show an increase in water elevation in relation to the original free surface prior to the wetdeck water impact. 
Thus designers should consider this in defining the air gap elevation, which is the minimal allowed distance between the calm water free surface and the wetdeck. This is illustrated in Figs. 17 and 22, where the equivalent calm water level for peak slam severity is shown.

Fig. 17:

The pressure results were obtained from the five pressure transducers located along the archway, with a constant relative angle of $11^{\circ}$ between the flat panel where the pressure transducers were installed and the horizontal free-surface, as presented in Figs. 2, 17 and 22.

It is interesting to note that P1 peaks at a time of approximately $34 \mathrm{~ms}$, confirming that the maximum local slam load occurred while the archway top is higher than the original undisturbed water surface. In addition there is a clear trend that the slam pressure moves towards the bow as the model becomes immersed further. As the slam pressure moves towards the bow, the peak magnitude decreases, despite a nearly constant relative velocity. These three dimensional effects are discussed in section 4.3.

The results for the other two impact velocities presented in Figs. 13 and 14 illustrate that the trends observed for $4 \mathrm{~m} / \mathrm{s}$ are consistent for the higher impact speeds of $5 \mathrm{~m} / \mathrm{s}$ and $4.5 \mathrm{~m} / \mathrm{s}$ respectively. These results therefore provide a full validation dataset for any future theoretical studies.

\subsection{Influence of impact velocity}

To study the effect of water-entry velocity on the slam force, tests were conducted for varying impact velocities. The slam force peak measurements of 25 successful water-impact tests are plotted against the square of corresponding impact velocities in 
Fig. 18. From these measurements the following expression was derived for maximum slam force $\left(F_{\max }\right)$ based on impact velocity:
$F_{\max }=571 v^{2}$
$[\mathrm{N}]$

Fig. 18:

This was derived with an R-square confidence of $96.6 \%$ and the trend line illustrates this strong dependency of total vertical force on impact velocity.

Fig. 19 illustrates the maximum error bounds in the total hydrodynamic slam force peaks corresponding to the square of the instantaneous impact velocities, against the load prediction equation. The variation of approximately $\pm 4 \%$ gives further evidence in the veracity of the observed relationship of the measured data.

Fig. 19:

Fig. 20 presents the pressure peaks for all the pressure transducers against the square of the corresponding impact velocities. The five subplots from (a) to (e) represent the measured peaks from P1 to P5 respectively, as well as the derived relationship expressions with a minimum confidence of $85 \%$. Although the points generally fit well with the derived trend lines, the results suggest that the slamming pressures are more sensitive to slight changes in velocity profile than are the slam forces. This is probably due to the relatively small transducer sensor area $\left(24.1 \mathrm{~mm}^{2}\right)$ making them sensitive to any small changes in the flow behaviour; whereas such small changes are not discernible in the force measurements. The increased magnitude of the pressure towards the aft the model is again shown in these plots and is likely due to the more confined nature of the archway here when compared to the bow region. 
Fig. 20:

\subsection{Three-dimensional Effect}

This section illustrates the importance of studying the wetdeck slamming problem as a three dimensional (3-d) phenomenon. The 3-d effect on slam peak pressures for varying impact velocities (from $2.5 \mathrm{~m} / \mathrm{s}$ to $5 \mathrm{~m} / \mathrm{s}$ in $0.5 \mathrm{~m} / \mathrm{s}$ increments) and the corresponding immersions and timings (occurrences) against the longitudinal locations of the five pressure transducers have been studied.

The mean values of slam pressure peaks of 25 water-impact tests are plotted against the longitudinal locations of five pressure sensors (equally distributed in y direction) in reference to the centrebow's aft truncation, in Fig. 21. The pressures can be seen to be strongly location dependent, with the maximum pressures at P1 (located aft at a longitudinal distance equal to $96.8 \mathrm{~mm}$ ) being approximately double that at the transducer furthest forward, P5 (at a distance of $251.6 \mathrm{~mm}$ ). As the slam pressure moves towards the bow, the peak magnitude decreases, despite a nearly constant relative velocity per each trend line and constant relative impact angle of $11^{\circ}$, as presented in Fig. 22.

Fig. 21:

The mean values for the instantaneous immersion, corresponding to the slam peak pressures for varying water impact velocities presented in Figs. 22 and 23, illustrate that the slam pressure peaks at an immersion level approximately $10.5 \%$ lower than the level equivalent to the original water-surface. This is due to the wetdeck slamming phenomenon being characterised by pre-collapsed spray jets, together with large free- 
surface deformations in the semi-enclosed volume beneath the wetdeck. The presented plots also illustrate that the trends observed in Fig. 17 for $4 \mathrm{~m} / \mathrm{s}$ are consistent for the whole tested conditions with a variation of less than $\pm 2 \%$. Fig. 22 illustrates also the slam peak pressure distributions along the arch way.

Fig. 22:

Fig. 23:

The three-dimensional effect has also been demonstrated by plotting the time variations between the slam pressure peaks in reference to $t_{o}$, as presented in Fig. 24, against the transducer longitudinal locations for all test conditions. A clear trend for the six impact velocities can be observed with the occurrence of the slam pressure peaks occurring later the further forward the transducer location is. The 3-d effects presented and discussed here would not have been captured in the model experiments if the model had been simplified to purely two dimensional sections.

Fig. 24:

\section{Conclusions}

This paper reported on a series of water impact experiments to investigate the hydrodynamic loads and pressures experienced by a generic wave-piercer catamaran hullform during water impacts. In contrast to previous model drop tests these experiments were conducted using a full three-dimensional model rather than twodimensional sections, and with a controlled velocity testing system. Since full details of the generic hull form are presented the results provide a comprehensive set of 
benchmarking data for use in the validation of numerical techniques to predict slam impact magnitudes of catamarans.

The systematic and random uncertainties associated with the drop test results were quantified in detail and demonstrated the excellent repeatability of the tests; for example the uncertainty of the measured peak slam loads was found to be less than $5 \%$.

The slam events were characterised by analysing the experimentally measured pressure, load and displacement and correlating this data with images from high-speed photographs. The maximum slam force was found to occur when the archway is filled with water, which occurs prior to the top of the archway reaching the original level of the water surface; thus suggesting that water builds up in the archway due to the immersion of the demihulls and centrebow. Designers should consider the increase in water elevation by approximately $10.5 \%$ in relation to the original water-surface prior to the wetdeck slamming event in defining the air gap elevation of catamarans.

A strong relationship between water-entry velocity and slam force was found and an empirical relationship is proposed to estimate the slam force magnitude as a function of the impact velocity: Fmax $=571 \mathrm{v}^{2}[\mathrm{~N}]$. This relationship is of importance for further validation studies to provide an estimate of the slam force for a broader range of relative impact velocities.

The pressure results showed that the pressure increased the further aft the transducer was located, suggesting that the more contained the archway is the greater the pressure. Empirical relationships for the maximum slam pressures are presented in relation to the vertical velocity at impact. 
The three dimensional effect on slam peak pressures and impact pulse timing has been investigated, showing that simplifying the wetdeck slam phenomenon as a quasi-2d problem can be considered to be an invalid assumption for such hull forms.

\section{Acknowledgements}

The authors acknowledge the ongoing support of Revolution Design and INCAT. The assistance of Callaghan Innovation, Auckland, New Zealand in providing access to the experimental facilities is gratefully appreciated. The Authors also recognise the work of Liam Honeychurch at the Australian Maritime College for constructing the experimental model.

\section{References}

Alaoui, A.E., Nême, A. and Scolan, Y.M. 2015. Experimental investigation of hydrodynamic loads and pressure distribution during a pyramid water entry. Journal of Fluids and Structures, 54, 925-935.

Battley, M. and Allen, T. 2012. Servo-hydraulic system for controlled velocity water impact of marine sandwich panels. Experimental Mechanics, 52(1), 95-106.

Chuang, S. 1966. Experiments on flat-bottom slamming. Journal of Ship Research, 10, $10-17$.

Davis, M.R. and Whelan, J.R. 2007. Computation of wet deck bow slam loads for catamaran arched cross sections. Ocean Engineering, 34(17), 2265-2276.

Djatmiko, E.B. 1992. Hydro-structural studies on swath type vessels. PhD, University of Glasgow.

DNV, 2010 Det Norske Veritas (DNV), 2010. Environmental conditions and environmental loads, RP-C205, 106.

Engle, A. and Lewis, R. 2003. A comparison of hydrodynamic impacts prediction methods with two dimensional drop test data. Marine Structures, 16(2), 175-182.

French, B.J., Thomas, G.A. and Davis, M.R. 2015. Slam occurrences and loads of a high-speed wave piercer catamaran in irregular seas. In: Proceedings of the 
Institution of Mechanical Engineers, Part M: Journal of Engineering for the Maritime Environment, 229(1), 45-57.

Graczyk, M. and Moan, T. 2008. A probabilistic assessment of design sloshing pressure time histories in LNG tanks. Ocean Engineering, 35, 834-855.

Huera-Huarte, F.J., Jeon, D. and Gharib, M. 2011. Experimental investigation of water slamming loads on panels. Ocean Engineering, 38(11), 1347-1355.

Jacobi, G., Thomas, G., Davis, M.R., Holloway, D.S., Davidson, G. and Roberts, T. 2012. Full-scale motions of a large high-speed catamaran: The influence of wave environment, speed and ride control system. International Journal of Maritime Engineering, 154(A3), A143-A155.

Jacobi, G., Thomas, G., Davis, M.R. and Davidson, G. 2014. An insight into the slamming behaviour of large high-speed catamarans through full-scale measurements. Journal of Marine Science and Technology, 19(1), 15-32.

Jalalisendi, M., Osma, S.J. and Porfiri, M. 2015a. Three-dimensional water entry of a solid body: A particle image velocimetry study. Journal of Fluids and Structures, 59, 85-102.

Jalalisendi, M., Shams, A., Panciroli, R. and Porfiri, M. 2015b. Experimental reconstruction of three-dimensional hydrodynamic loading in water entry problems through particle image velocimetry. Experiments in fluids, 56 (2), 117.

Kapsenberg, G. 2011. Slamming of ships: where are we now? Philosophical Transactions of the Royal Society A: Mathematical, Physical and Engineering Sciences, 369(1947), 2892-2919.

Lavroff, J., Davis, M., Holloway, D. and Thomas, G. 2011. Determination of wave slamming loads on high-speed catamarans by hydroelastic segmented model experiments. International Journal of Maritime Engineering, 153, 185-197.

Lewis, S.G., Hudson, D.A., Turnock, S.R. and Taunton, D.J. 2010. Impact of a freefalling wedge with water: synchronized visualization, pressure and acceleration measurements. Fluid Dynamics Research, 42(3), 035509.

Mitra, S.K. and Kuo, Y. 2006. Digital signal processing: a computer-based approach, New York, McGraw-Hill, 422.

Ochi, M.K. and Motter, L.E. 1971. A method to estimate slamming characteristic for ship design. Marine Technology, SNAME, 8(2), 219-232.

Panciroli, R., Abrate, S., Minak, G. and Zucchelli, A. 2012. Hydroelasticity in waterentry problems: Comparison between experimental and SPH results. Composite Structures, 94 (2), 532-539. 
Panciroli, R. 2013. Hydroelastic impacts of deformable wedges. Solid Mechanics and its Applications, 192, 1-45.

Panciroli, R., Abrate, S. and Minak, G. 2013. Dynamic response of flexible wedges entering the water. Composite Structures, 99, 163-171.

Panciroli, R., Ubertini, S., Minak, G. and Jannelli, E. 2015. Experiments on the Dynamics of Flexible Cylindrical Shells Impacting on a Water Surface. Experimental mechanics, 55 (8), 1537-1550.

Pistani, F. and Thiagarajan, K. 2012. Experimental measurements and data analysis of the impact pressures in a sloshing experiment. Ocean Engineering, 52, 60-74.

Rothe, F., Sames, P.C. and Schellin, T.E. 2001. Catamaran wetdeck structural response to wave impact. In: Proceedings of the International Conference of Fast Sea Transportation (FAST'01), Southampton, England, 125-133.

Stenius, I., Rosén, A., Battley, M. and Allen, T. 2013. Experimental hydroelastic characterization of slamming loaded marine panels. Ocean Engineering, 74, 115 .

Swidan, A., Thomas, G., Ranmuthugala, D., Penesis, I. and Amin, W. 2014. Numerical investigation of water slamming loads on wave-piercing catamaran hull model. In: Proceedings of the $10^{\text {th }}$ Symposium on High Speed Marine Vessels (HSMV), Naples, Italy, 1-9.

Thomas, G., Davis, M., Holloway, D. and Roberts, T. 2002. Extreme asymmetric slam loads on large high speed catamarans. In: Proceedings of the $6^{\text {th }}$ Symposium of High Speed Marine Vessels, Naples, Italy, 15-23.

Thomas, G., Kibby, L., Ford, A., Binns, J., Finnie, I. and Kavanagh, N. 2011. Experimental Investigation into Wave-Induced Design Loads on a Large Moored Catamaran. Ships and Offshore Structures, 6, 273-295.

Tveitnes, T., Fairlie-Clarke, A. and Varyani, K. 2008. An experimental investigation into the constant velocity water entry of wedge-shaped sections. Ocean Engineering, 35(14), 1463-1478.

Van Nuffel, D., Vepa, K., De Baere, I., Degrieck, J., De Rouck, J. and Van Paepegem, W. 2013. Study on the parameters influencing the accuracy and reproducibility of dynamic pressure measurements at the surface of a rigid body during water impact. Experimental mechanics, 53, 131-144.

Whelan, J.R. 2004. Wetdeck slamming of high speed catamarans with a centrebow. $\mathrm{PhD}$, Univesrsity of Tasmania, Tasmania, Australia.

Yamamoto, Y., Iida, K., Fukasawa, T., Murakami, T., Arai, M. and Ando, A. 1985. Structural damage analysis of a fast ship due to bow flare slamming. International shipbuilding progress, 32, 124-136. 


\section{Figure Captions}

Fig. 1: Profile view of hydraulic test installation (dimensions in $\mathrm{mm}$ ).

Fig. 2: Body lines of generic catamaran hull form, also showing the locations of the five pressure transducers.

Fig. 3: Test model instrumented with three load cells and five pressure transducers. All spaces were filled with expanding foam prior to testing.

Fig. 4: Test model installed on the centreline of the moving test fixture.

Fig. 5: The instrumented test model and spatial distribution of gauges $(\mathrm{P}=$ pressure transducer while LC $=$ load cell).

Fig. 6: Repeatability of three tests for target velocity of $4.5 \mathrm{~m} / \mathrm{s}$; (a) immersion, (b) velocity profile, (c) pressure transducer and (d) total impact load.

Fig. 7: Immersion and velocity time histories of repeated tests at target velocity equal to $4 \mathrm{~m} / \mathrm{s}$.

Fig. 8: Total hydrodynamic load time histories of repeated tests at target velocity equal to $4 \mathrm{~m} / \mathrm{s}$.

Fig. 9: Hydrodynamic pressure time-series of $\mathrm{P} 1$ at target velocity equal to $4 \mathrm{~m} / \mathrm{s}$.

Fig. 10: Evolution of water-jets from the centrebow and demihull prior to wetdeck slamming event for a target velocity of $4 \mathrm{~m} / \mathrm{s}$.

Fig. 11: Error bound of water impact velocity for the target velocity.

Fig. 12: Comparison of raw load signals from three load cells during $4 \mathrm{~m} / \mathrm{s}$ water-entry with filtered data with a cut-off frequency of $500 \mathrm{~Hz}$.

Fig. 13: Time-history of measured data (target velocity of $5 \mathrm{~m} / \mathrm{s}$ ), (a) immersion, (b) velocity, (c) total hydrodynamic load and measured forces from three load cells, (d) pressure trace from P1 to P5.

Fig. 14: Time-history of measured data (target velocity of $4.5 \mathrm{~m} / \mathrm{s}$ ), (a) immersion, (b) velocity, (c) total hydrodynamic load and measured forces from three load cells, (d) pressure trace from P1 to P5. 
Fig. 15: Time-history of measured data (target velocity of $4 \mathrm{~m} / \mathrm{s}$ ), (a) immersion, (b) velocity, (c) total hydrodynamic load and measured forces using three load cells, (d) pressure trace from P1 to P5, while '^’' marker corresponds to images in Fig. 16.

Fig. 16: Frames taken by high-speed camera $3000 \mathrm{fps}$ (frame per second) correspond to '^’ markers in Fig. 15(c).

Fig. 17: Bow view of model showing immersions (130 and $159 \mathrm{~mm}$ ) that correspond to the peaks of slam pressure and slam force respectively ( $4 \mathrm{~m} / \mathrm{s}$ water-entry) in relation to the original water-surface. Also shown on the starboard side are the locations of the five pressure transducers.

Fig. 18: Relationship between slam force peak and the square of the instantaneous vertical velocity at impact.

Fig. 19: The measured slam force peak error bounds corresponding to the square of instantaneous impact velocities against the slam load prediction equation, as illustrated in Fig. 18.

Fig. 20: Pressure peaks for the five pressure transducers plotted against the square of corresponding impact velocities. Subplots from (a) to (e) are for P1 to P5 respectively.

Fig. 21: Mean pressure peaks corresponding to six relative velocities against the distance $y$ in reference to the centrebow aft truncation. Vertical bars indicate standard deviation.

Fig. 22: Profile view of model showing immersions corresponding to the slam pressure peaks. Also shown on the archway are the locations of the five pressure transducers.

Fig. 23: Mean model immersions correspond to slam pressure peaks of all test conditions against the distance $\mathrm{y}$ in reference to the centrebow truncation.

Fig. 24: Mean timings that correspond to the peak slam pressures of five pressure transducers at six relative velocities against the distance y in reference to the centrebow truncation. 


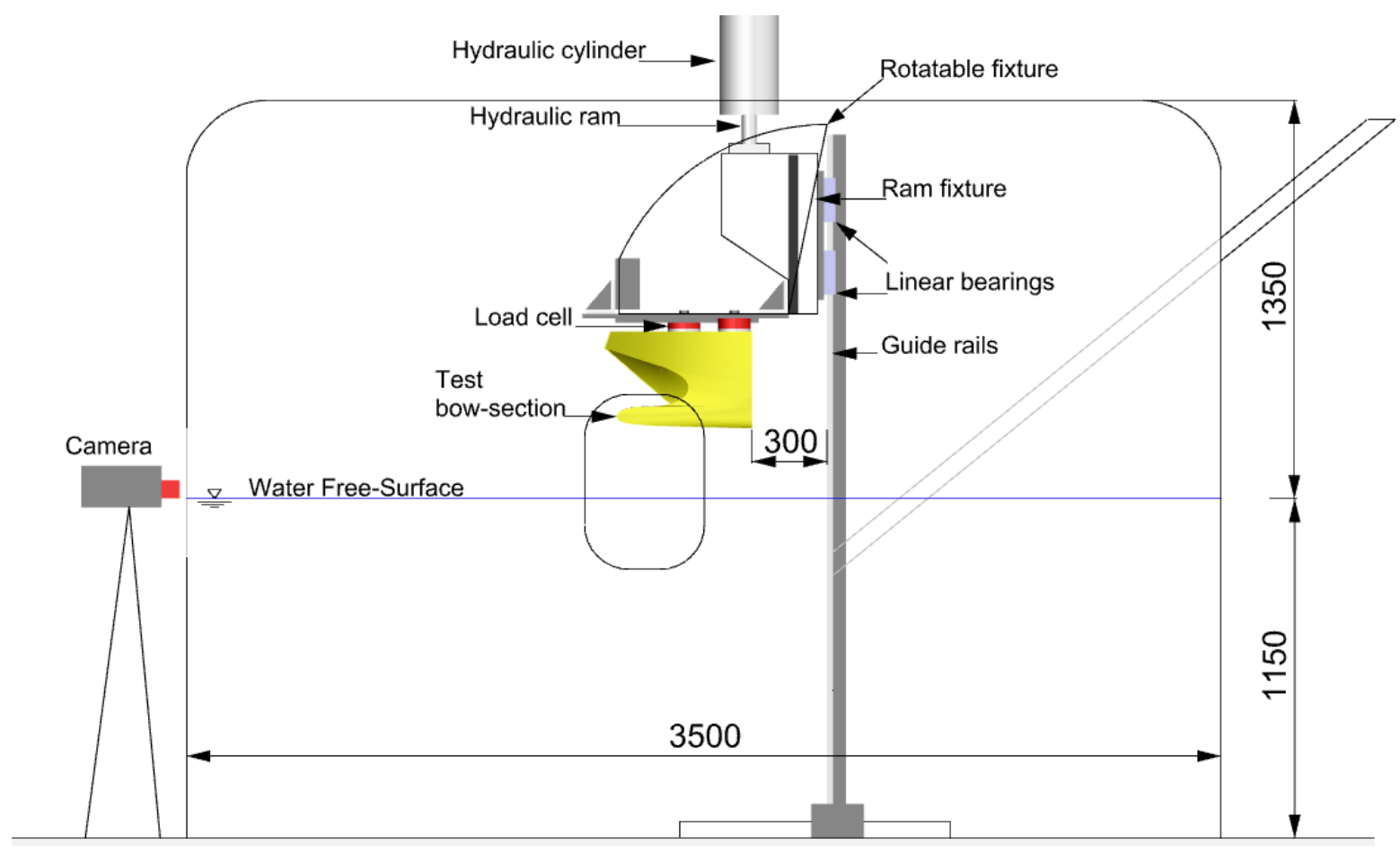

Fig. 25:

1.5-column fitting image

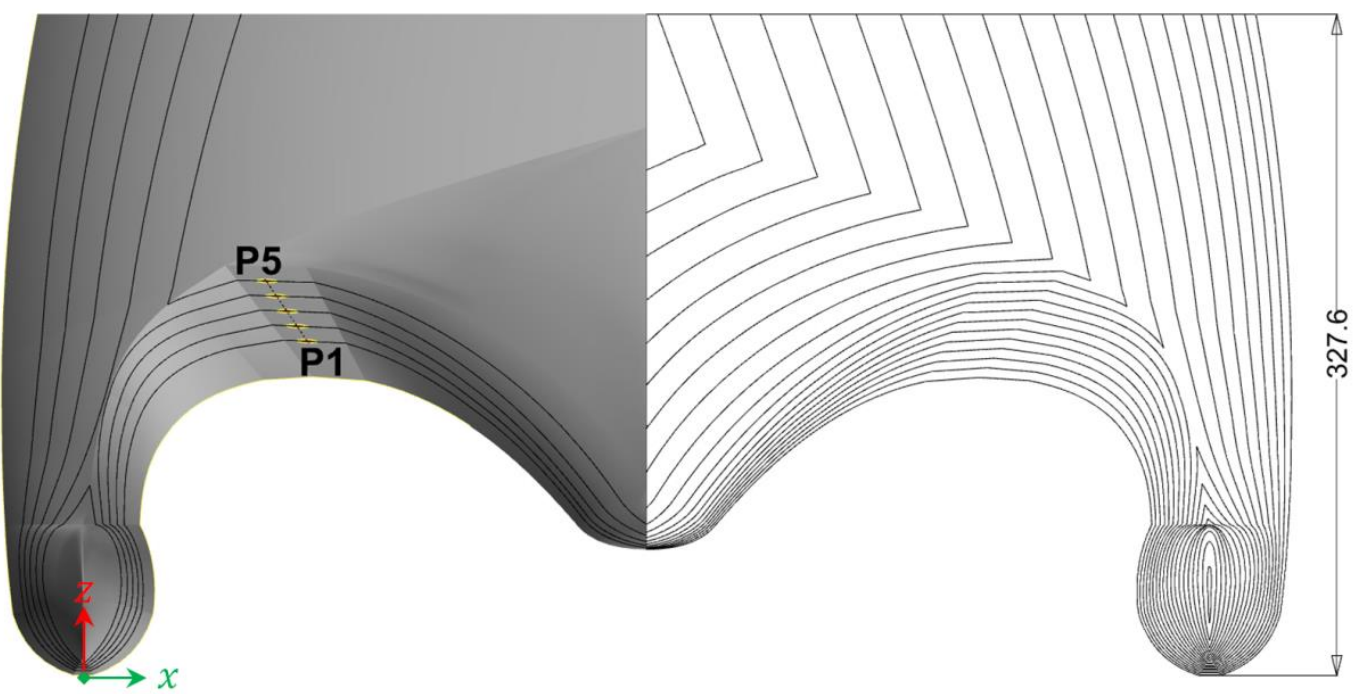

Fig. 26:

1.5-column fitting image 


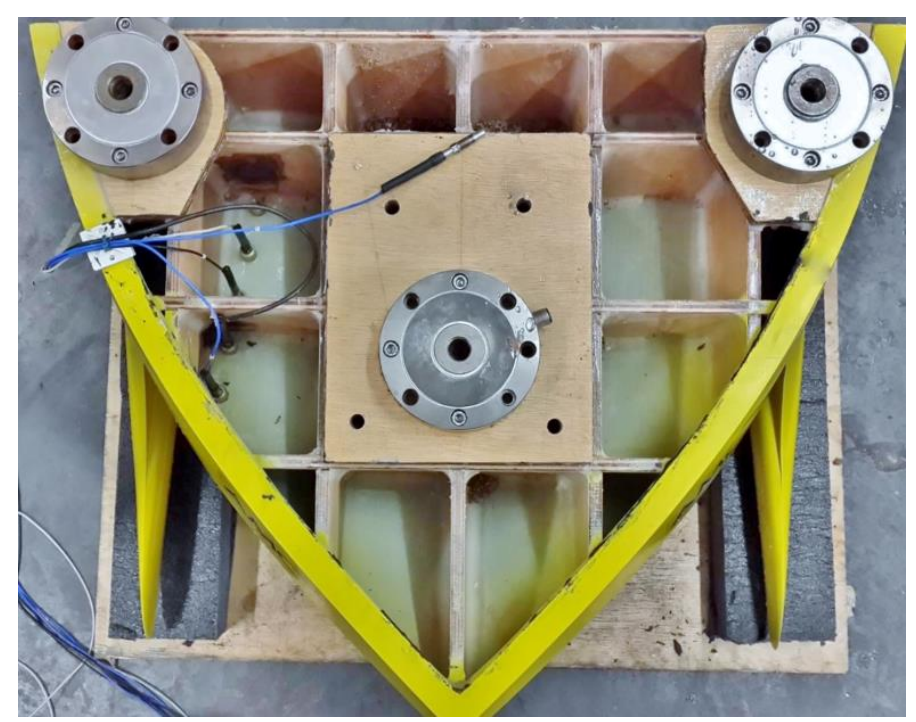

Fig. 27:

1-column fitting image

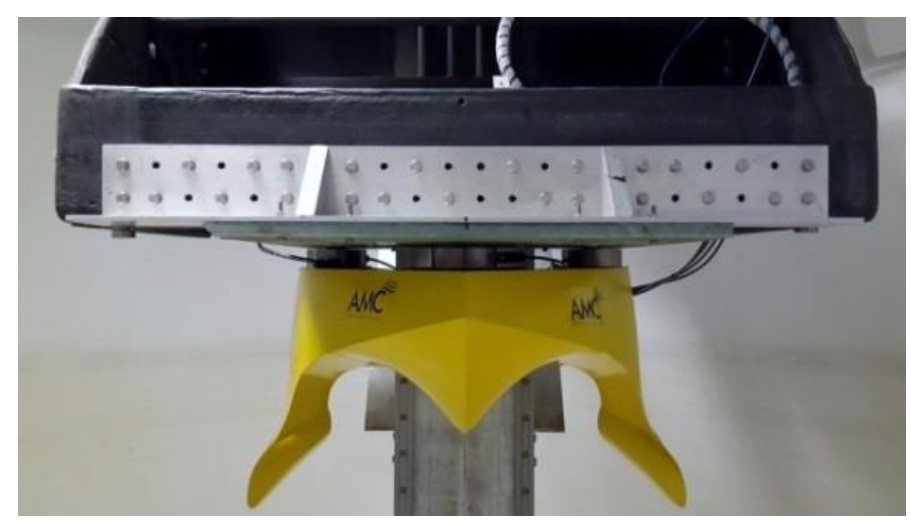

Fig. 28:

1-column fitting image

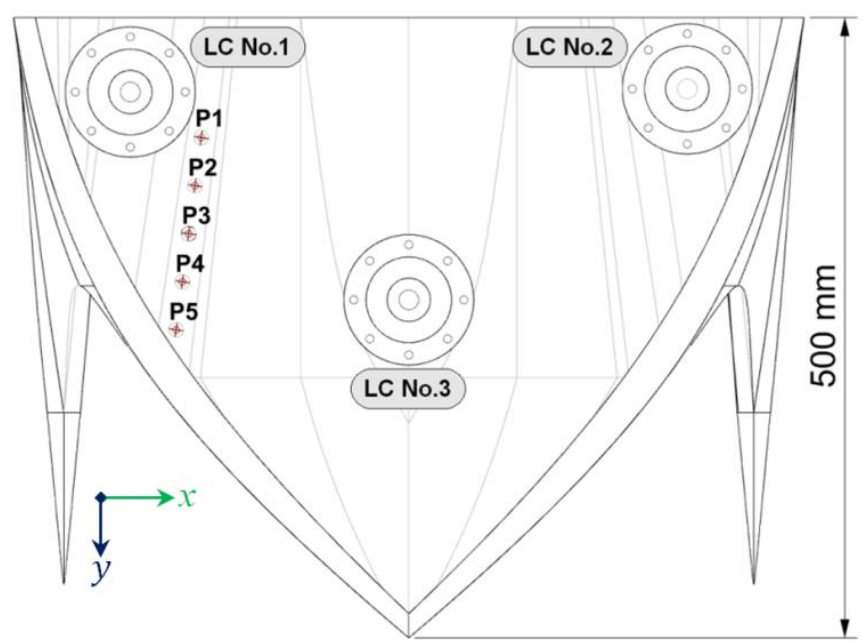

Fig. 29:

1-column fitting image 

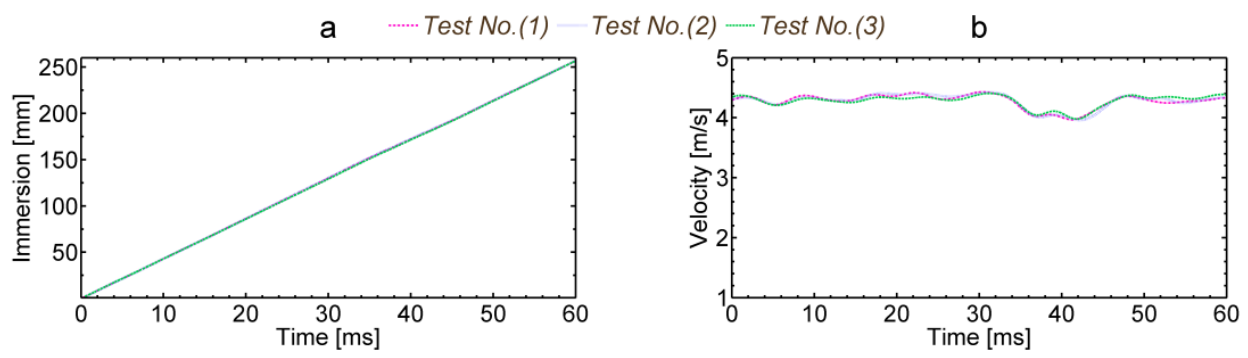

C
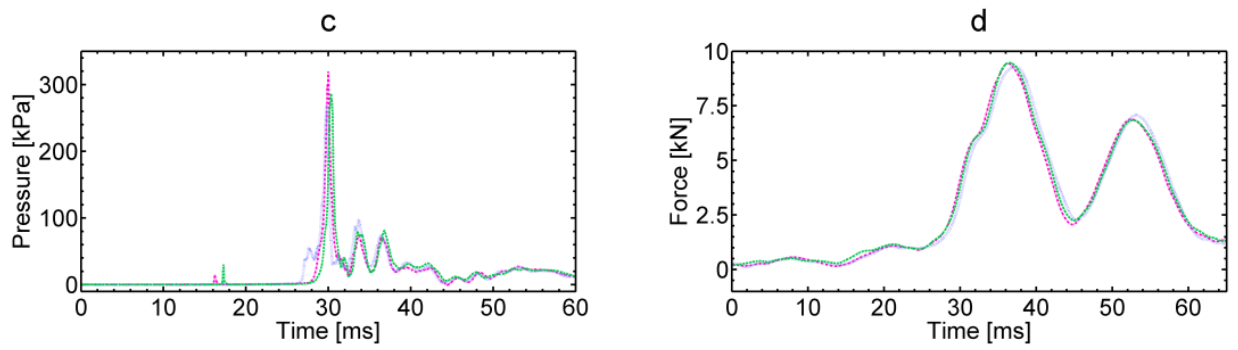

Fig. 30:

1.5-column fitting image

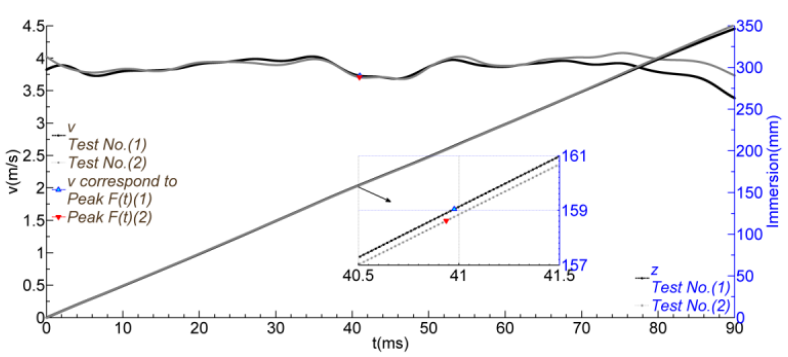

Fig. 31:

1-column fitting image

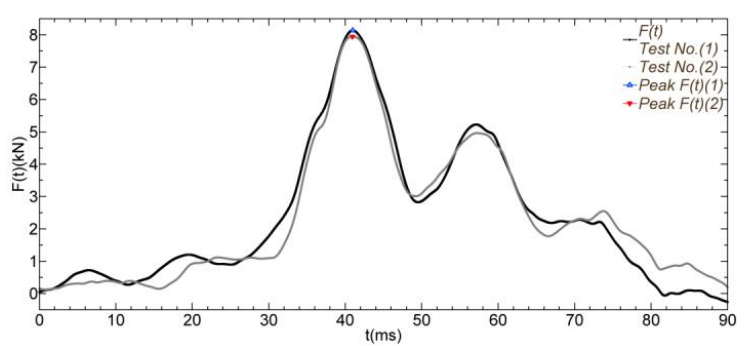

Fig. 32:

1-column fitting image 


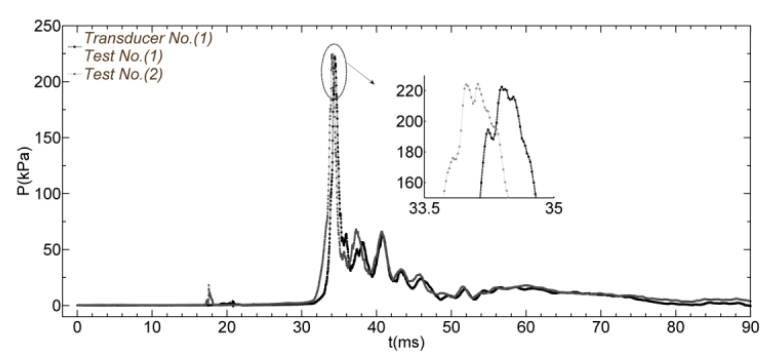

Fig. 33:

1-column fitting image

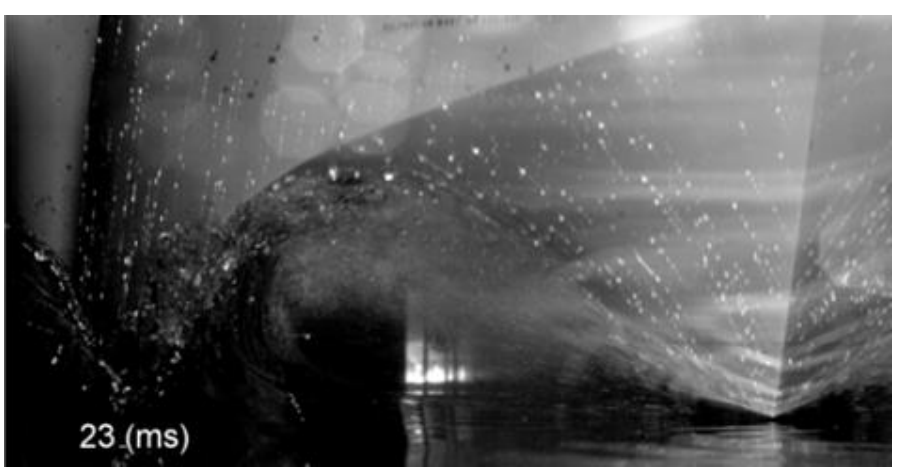

Fig. 34:

1-column fitting image

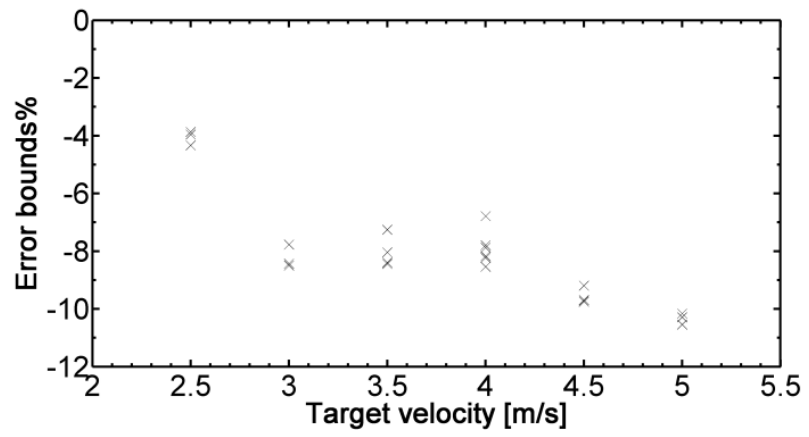

Fig. 35:

1-column fitting image

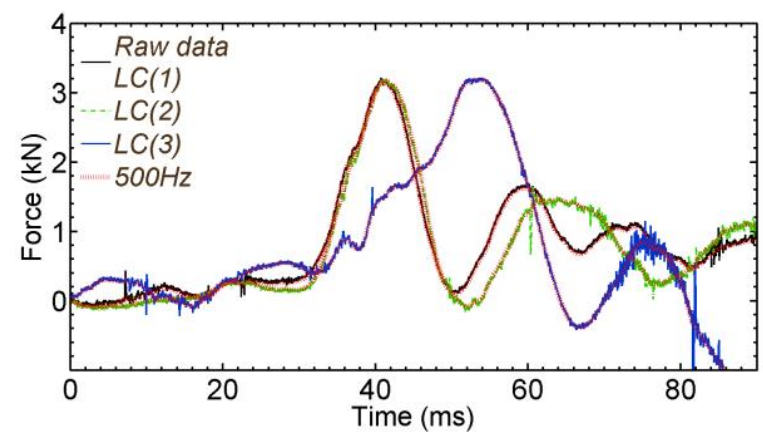

Fig. 36:

1-column fitting image 
a
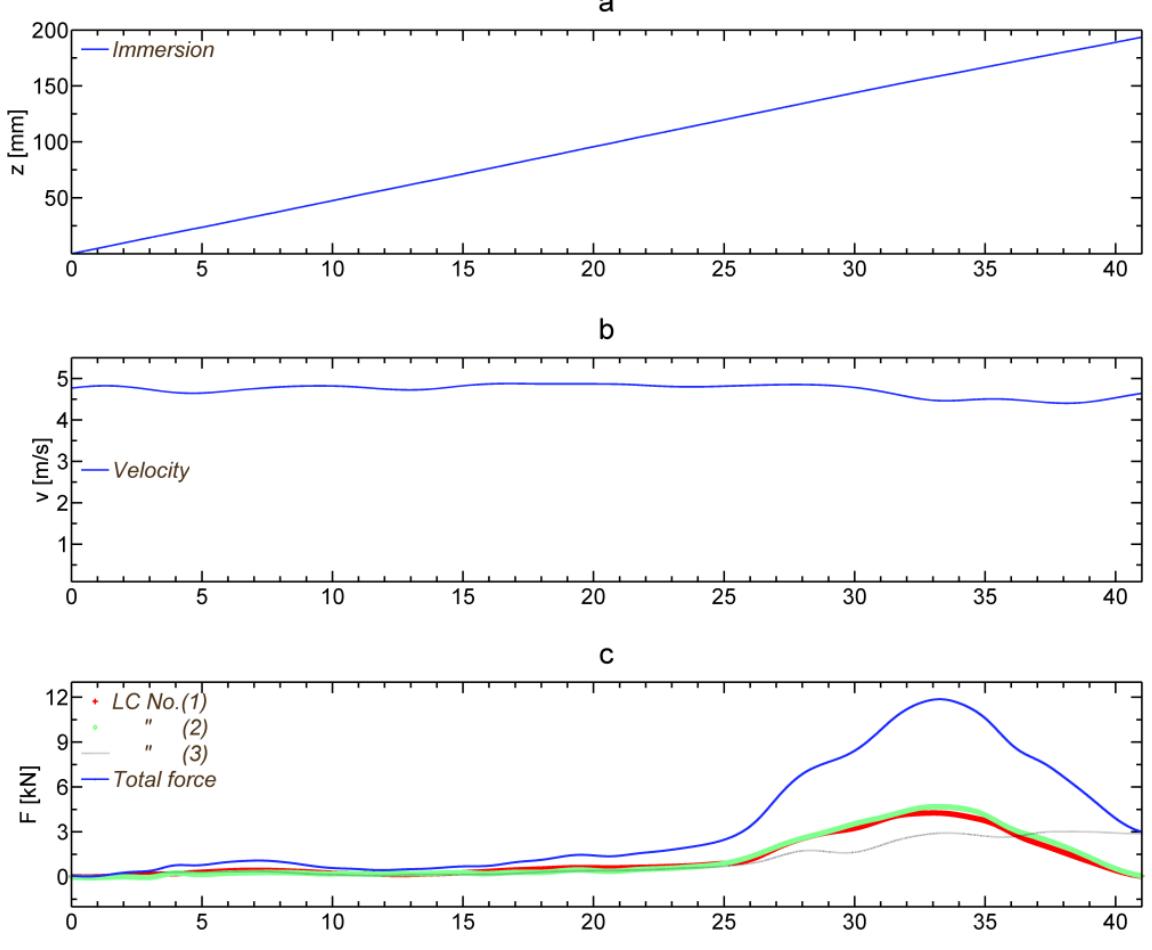

d

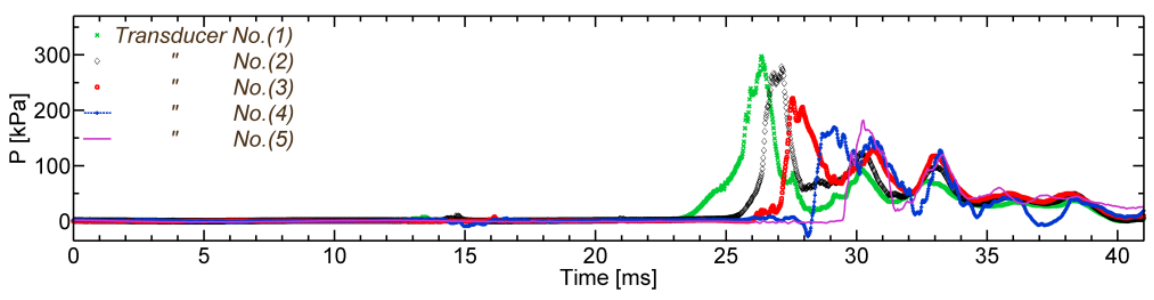

Fig. 37:

1.5-column fitting image 
a
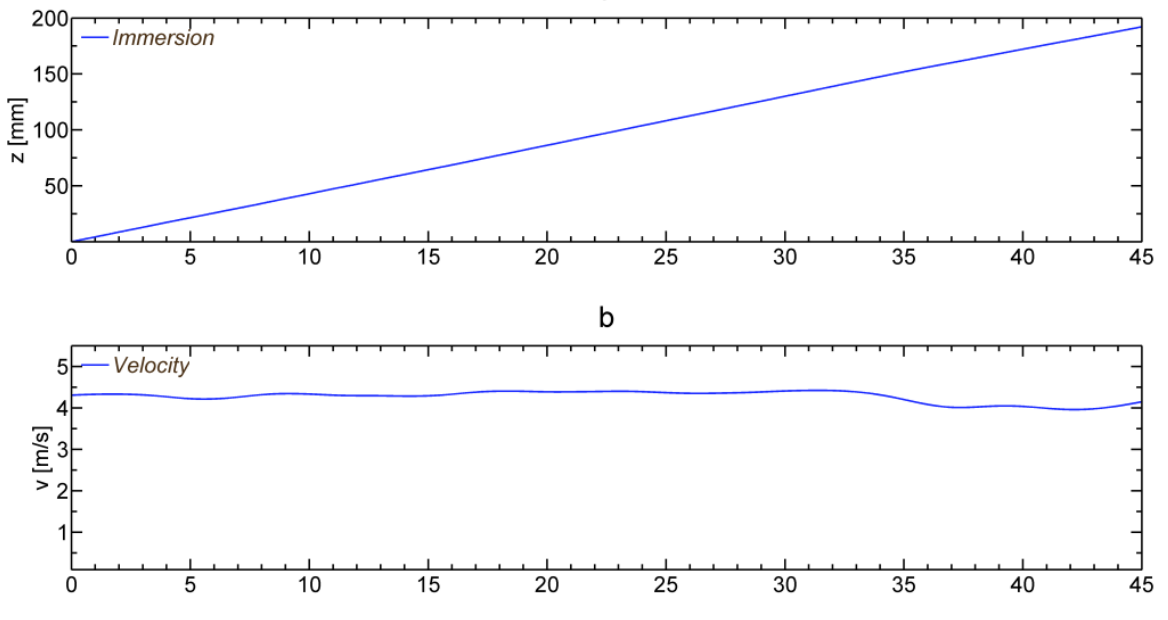

C

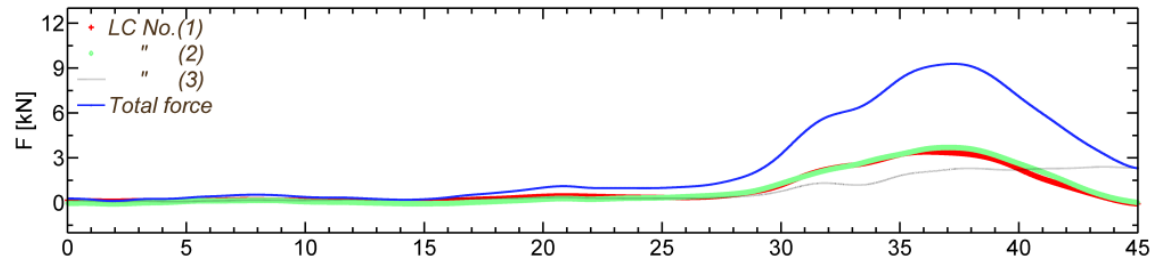

d

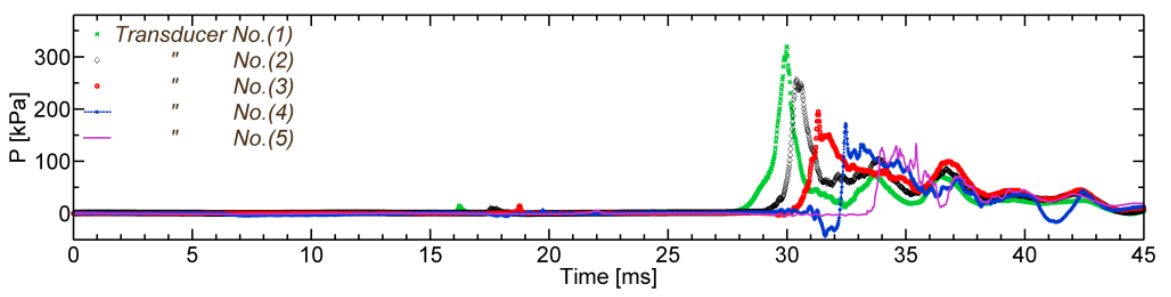

Fig. 38:

1.5-column fitting image

Page |31 
a

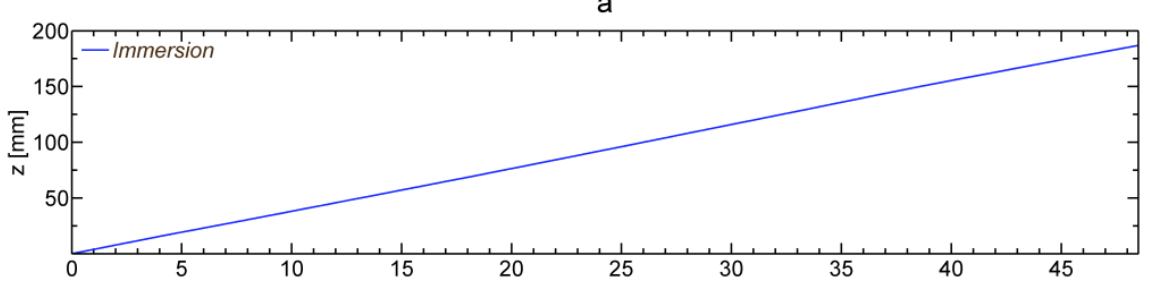

b

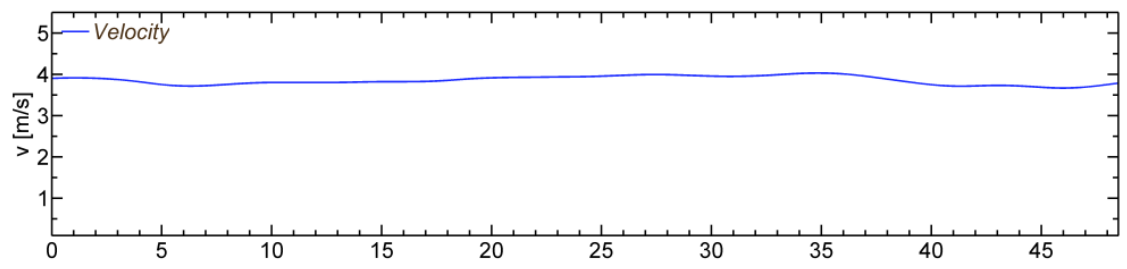

C

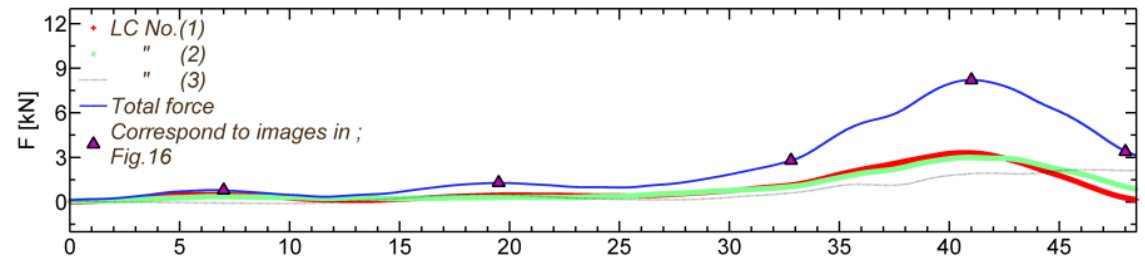

d

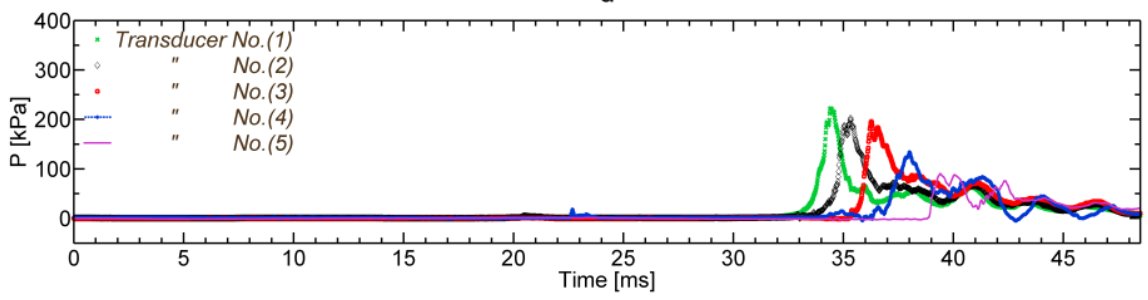

Fig. 39:

1.5-column fitting image

Page |32 

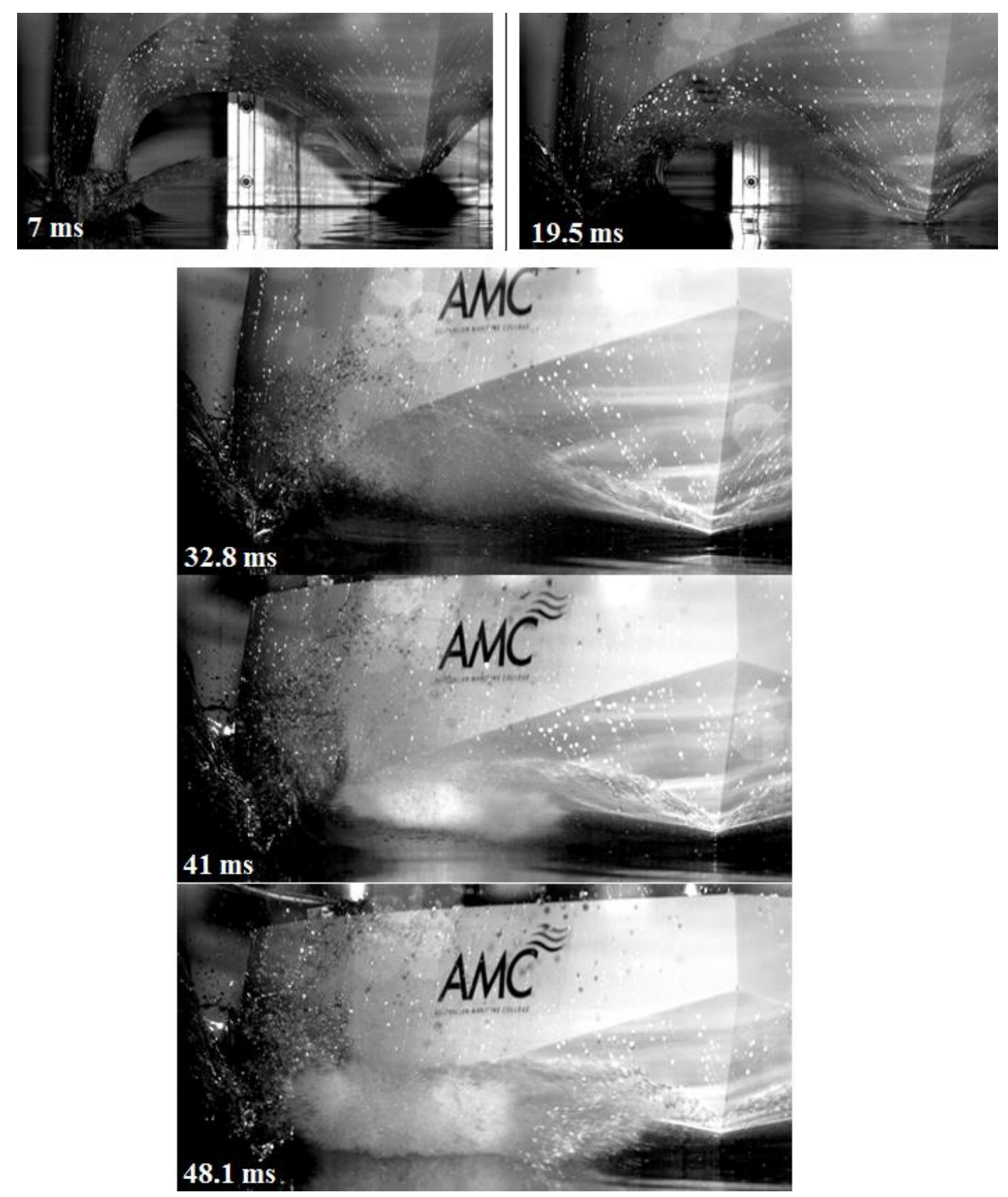

Fig. 40:

1.5-column fitting image 


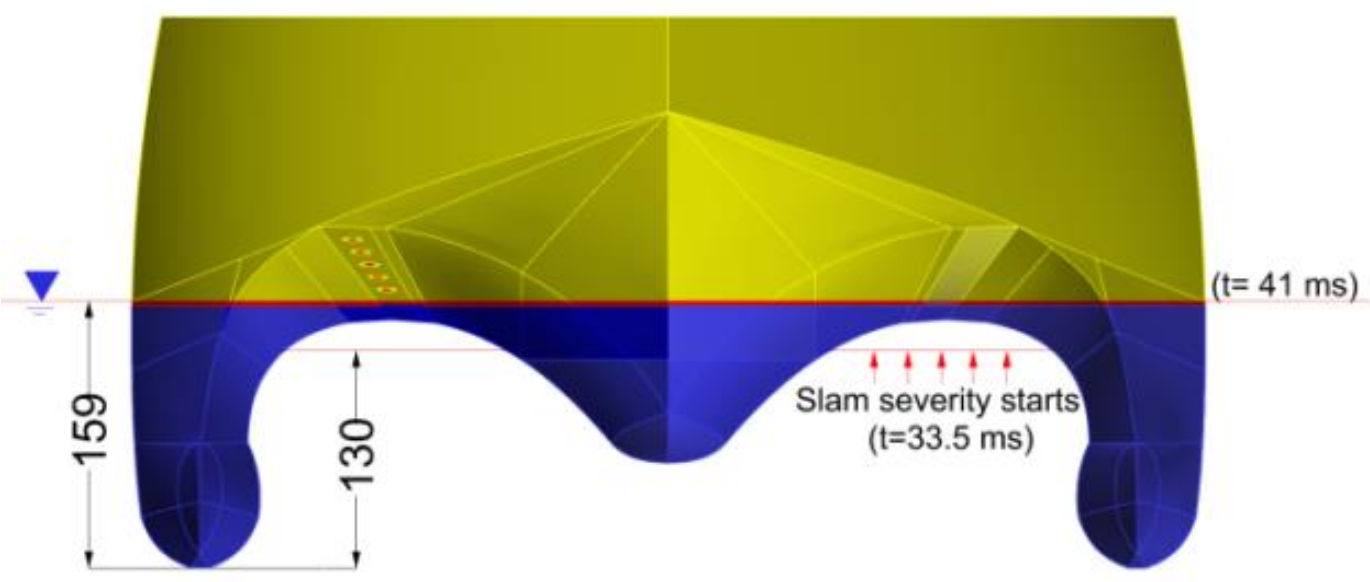

Fig. 41:

1-column fitting image

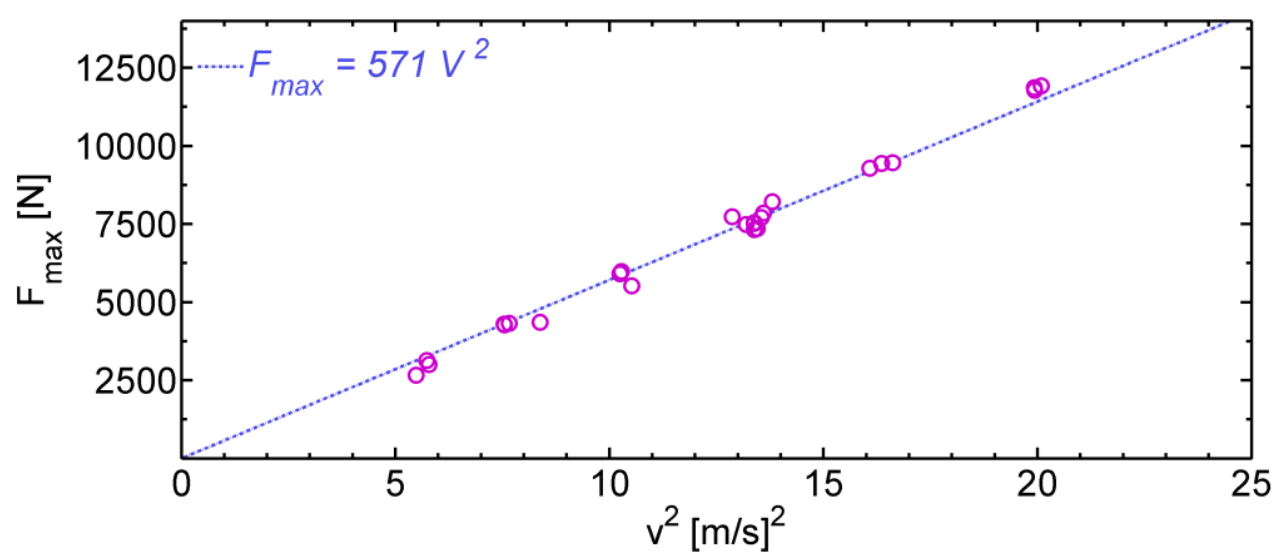

Fig. 42:

1.5-column fitting image

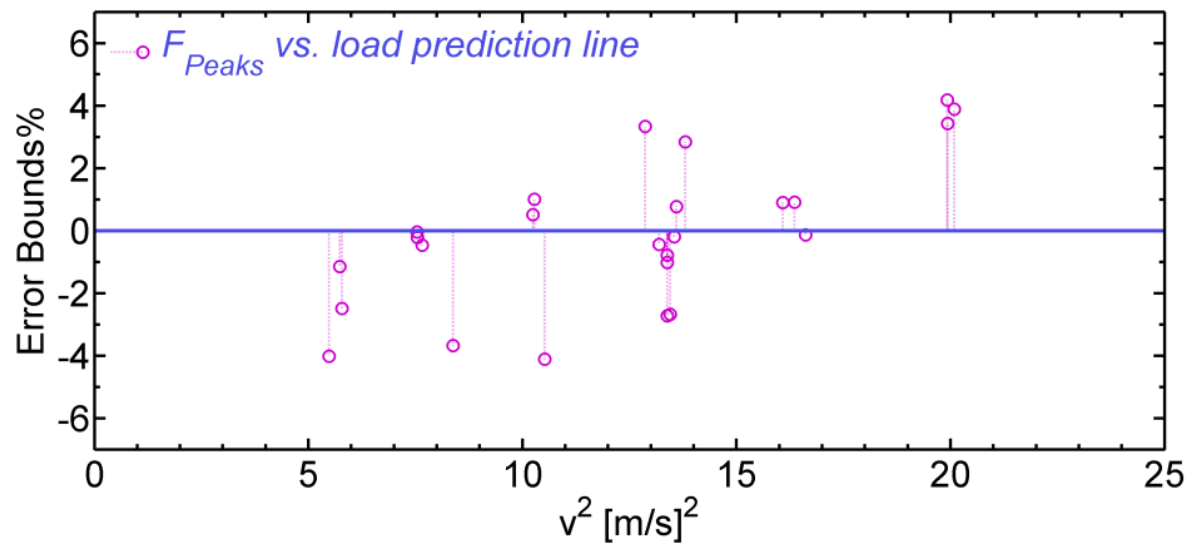

Fig. 43:

1.5-column fitting image 

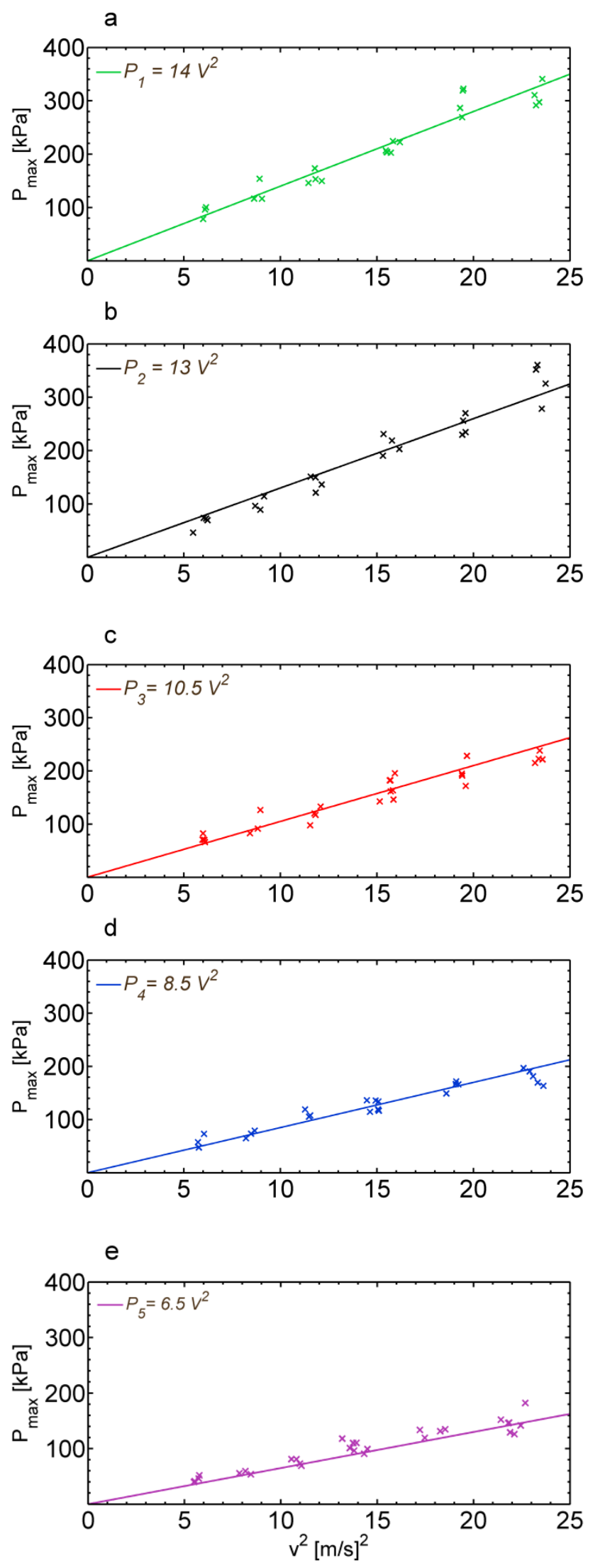

Fig. 44:

1-column fitting image

Page |35 


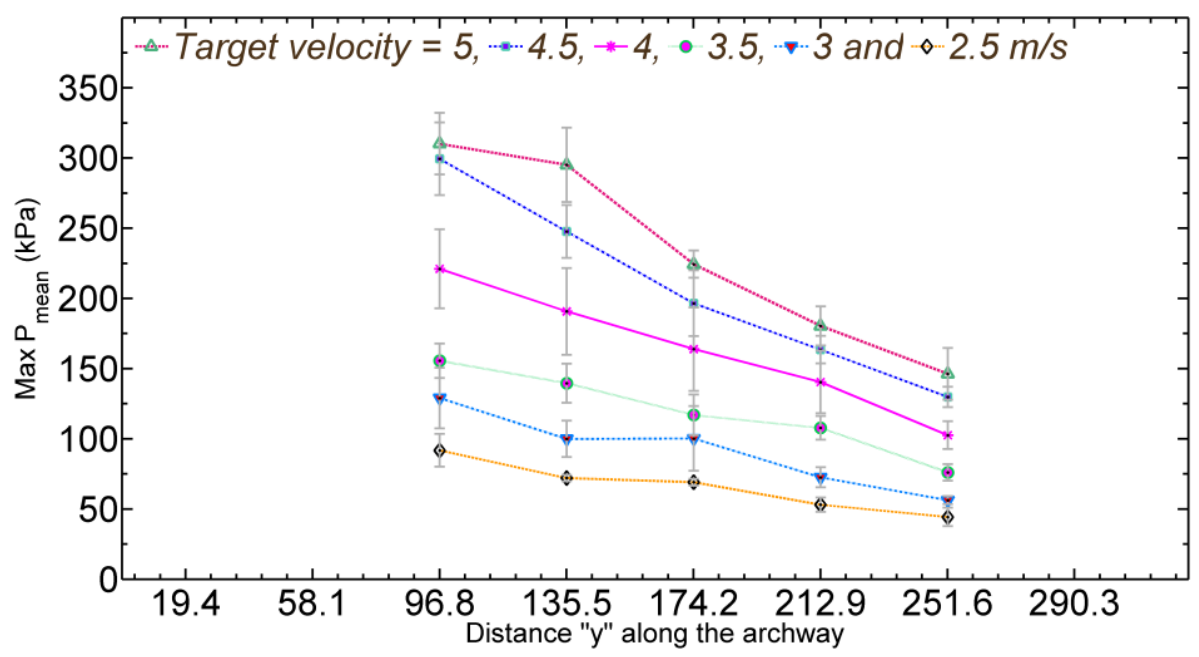

Fig. 45:

1.5-column fitting image

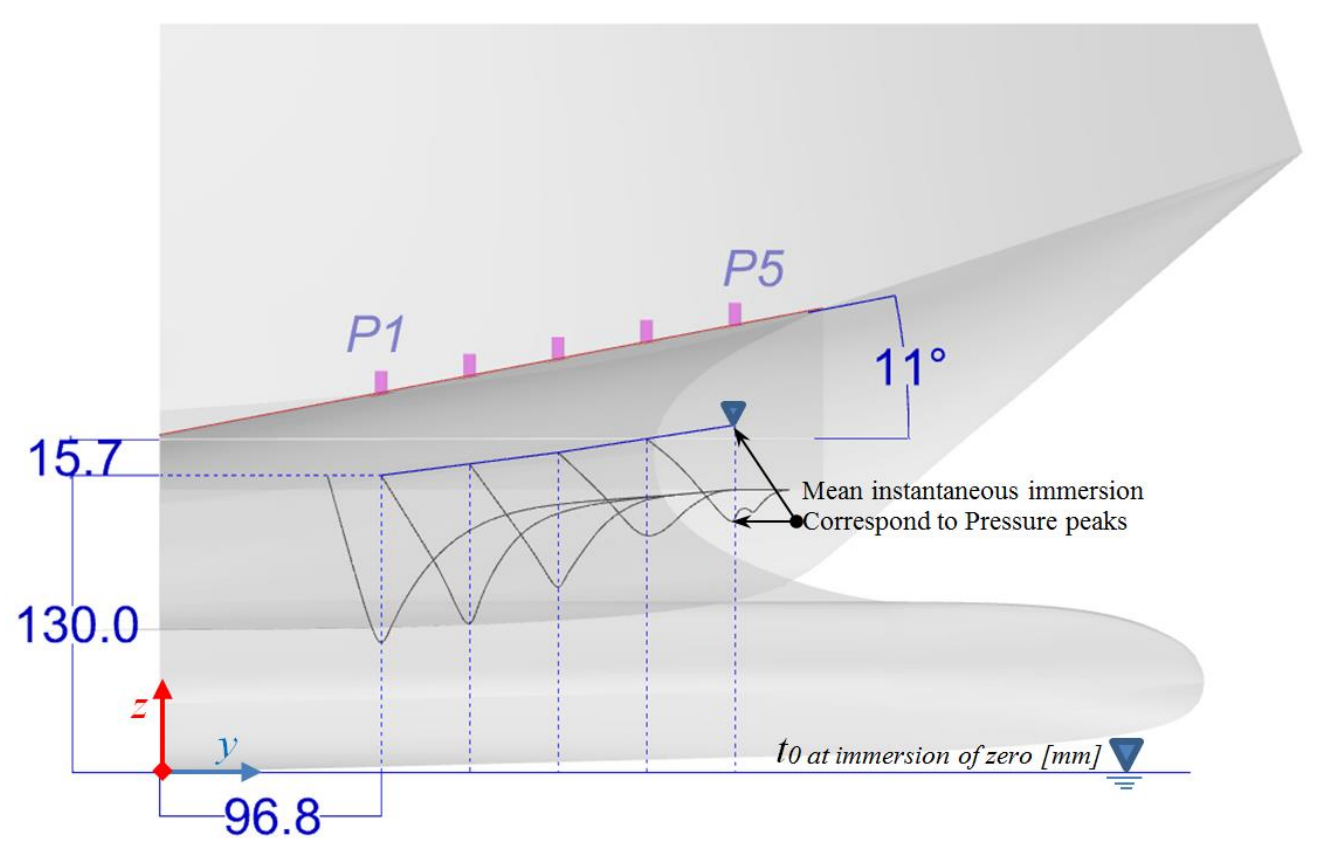

Fig. 46:

1.5-column fitting image 


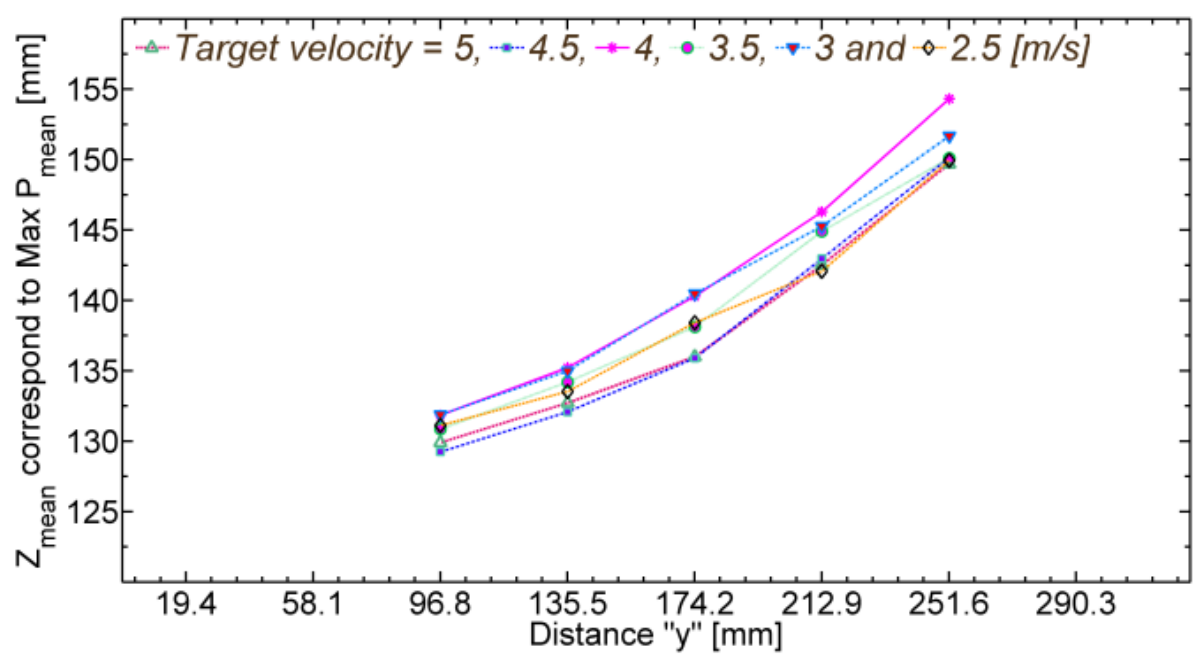

Fig. 47:

1.5-column fitting image

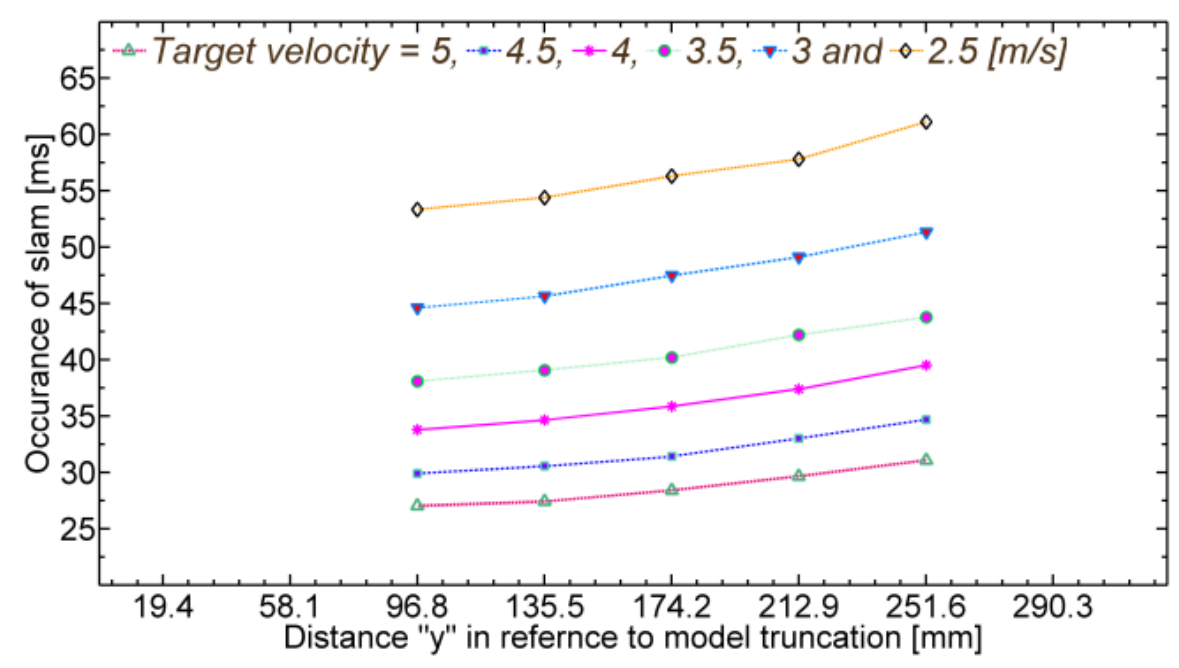

Fig. 48:

1.5-column fitting image 


\section{Table Captions}

Table 1: Details of Gauges

Table 2: Location of Pressure Transducers

Table 3: Summary of Test Conditions

Table 4: Summary of Systematic Errors

Table 5:

\begin{tabular}{llllll}
\hline Gauge & $\begin{array}{l}\text { No. of } \\
\text { Channels }\end{array}$ & Manufacturer & Model & $\begin{array}{l}\text { Maximum } \\
\text { Range }\end{array}$ & Total Error \% \\
\hline Load cell & 3 & $\begin{array}{l}\text { Precision } \\
\text { transducers }\end{array}$ & LPC 5t & $5000 \mathrm{~kg}$ & 1.25 \\
Pressure & 5 & PCB & $113 \mathrm{~B} \mathrm{26}$ & 68950 & 2.9 \\
$\begin{array}{l}\text { Transducers } \\
\text { Position }\end{array}$ & 1 & Piezotronics & & $\mathrm{kNm}-2$ & \\
sensor & Vishay & REC 139 & $3 \mathrm{~m}$ & 2.2 \\
\hline
\end{tabular}

Table 6:

\begin{tabular}{llll}
\hline $\begin{array}{l}\text { Transducer } \\
\text { / Location }\end{array}$ & $x(\mathrm{~mm})$ & $y(\mathrm{~mm})$ & $\mathrm{z}(\mathrm{mm})$ \\
\hline P1 & 111.06 & 96.82 & 165.62 \\
P2 & 105.98 & 135.53 & 173.08 \\
P3 & 100.9 & 174.25 & 180.53 \\
P4 & 95.82 & 212.95 & 187.99 \\
P5 & 90.74 & 251.67 & 195.45 \\
\hline
\end{tabular}


Table 7:

\begin{tabular}{llll}
\hline Condition & $v_{\text {target }}$ & $v_{\text {impact }}$ & $\begin{array}{l}v_{\text {std } x} \\
100\end{array}$ \\
units & $(\mathrm{m} / \mathrm{s})$ & $(\mathrm{m} / \mathrm{s})$ & \\
\hline 1 & 2.5 & 2.39 & 0.6 \\
2 & 3 & 2.76 & 1 \\
3 & 3.5 & 3.22 & 1.7 \\
4 & 4 & 3.72 & 1.9 \\
5 & 4.5 & 4.05 & 2.3 \\
6 & 5 & 4.45 & 0.8 \\
\hline
\end{tabular}

Table 8:

\begin{tabular}{llll}
\hline Error source/ Gauge & Ram position & Load cell & Pressure transducer \\
\hline Linearity Error (\%) & \pm 1 & 0.05 & 1 \\
Acquisition System (\%) & 1.2 & 1.2 & 1.9 \\
\hline Total (\%) & 2.2 & 1.25 & 2.9 \\
\hline
\end{tabular}

